\title{
Mathematical Simulation of the Synchronized Asynchronous Electric Drive
}

\author{
Victor Meshcheryakov ${ }^{1, *}$, Dmitry Sibirtsev ${ }^{1}$, and Ekaterina Mikhailova ${ }^{2}$ \\ ${ }^{1}$ Lipetsk State Technical University, Department of Electric Drives, Lipetsk, Russia \\ ${ }^{2}$ Kazan State Power Engineering University, Department of Power Stations, Kazan, Russia
}

\begin{abstract}
At the end of the last century asynchronous motors with a phase rotor were most widely used among adjustable-speed AC drives. They were used for conveyors, transporters, cranes. That was due to the relative simplicity to adjust the motor speed by acting on the rotor chain. The introduction of a frequency control method in such drives is now complicated by the fact that most frequency converters are designed to be used in drives with a cage asynchronous motor. Shorting of a phase winding leads to highly increased losses during acceleration and motor speed control. If the stator winding of a wound-rotor asynchronous motor is connected to a frequency converter and the rotor winding is connected to a DC link of this converter, the motor will have properties of a synchronous one. The electric drive is able to work in a wide range, while motor characteristics are absolutely rigid. The implementation of such control method is presented in this article. The control system operation has been tested with simulation in the Matlab Simulink software pack. The obtained results are defined as follows.
\end{abstract}

\section{Introduction}

There is a number of production mechanisms that require control systems to obtain absolutely rigid performance characteristics and a wide range of speed control. In such mechanisms it is advisable to use a synchronized electric drive based on a wound-rotor asynchronous motor $[1,2]$. A wound-rotor asynchronous motor is put into synchronous mode by supplying a direct current to the rotor winding [3]. Since DC flows through the rotor windings of the motor and the rotor speed of the motor does not depend on the load on the shaft, which is typical for a synchronous machine, the wound-rotor asynchronous motor operating in such mode is called synchronized [3]. The synchronous mode of the motor has among others one advantage over the asynchronous mode which is the ability of the motor to change the magnitude and mark of the reactive power when adjusting the magnitude of the excitation current [4]. With direct connection of the stator winding to the supply mains providing motor overexcitation, reactive power is supplied to the supply mains network and, if underexcited, is consumed from the network, there is therefore a fundamental possibility of influencing the energy exchange process between the motor and the power supply system by controlling the excitation current of powerful synchronized asynchronous motors [5].

\section{Approaches}

The connection diagram of the synchronized motor is shown in Fig. 1. The rotor winding is connected to a constant-voltage source in accordance with the diagram shown in the figure. The diodes in the diagram are used to exclude free currents in a closed circuit formed by two paralleled rotor windings. On completing the electromechanical transient process, connected with the start-up of the electric drive and retraction of the motor in synchronism, the motor continues to work in a static mode, possessing all the characteristics of a synchronous nonsalient pole motor of the classical type.

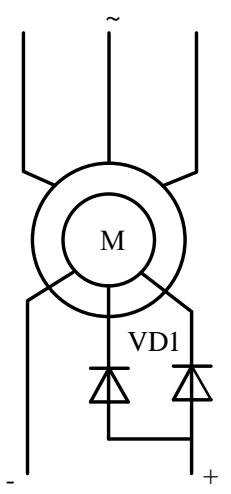

Fig. 1. The connection diagram of the synchronized asynchronous motor. 


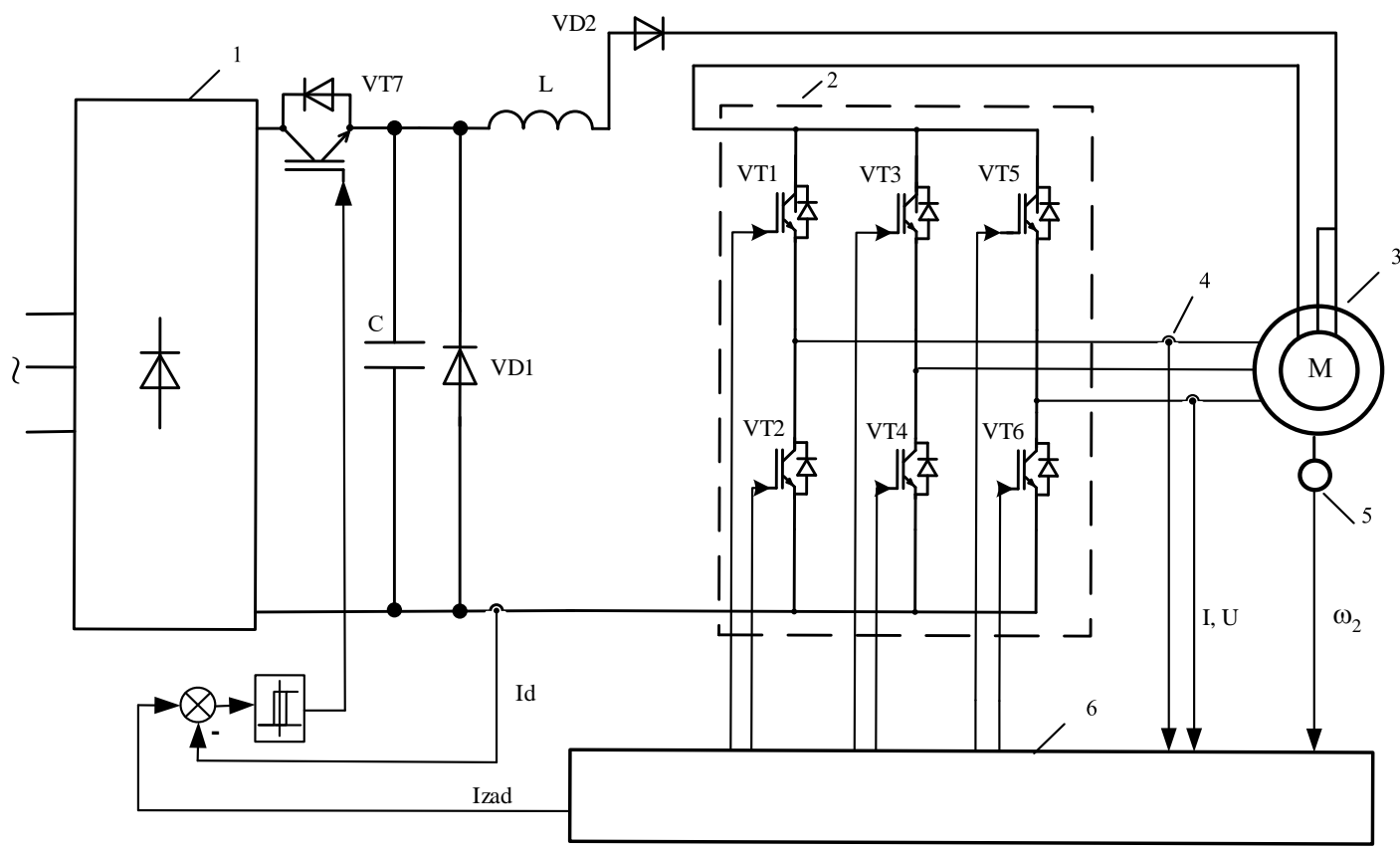

Fig. 2. Connection diagram of the synchronized motor.

A wound-rotor asynchronous motor operating in synchronous mode requires an accurate setting of the acceleration rate with its correction when the moment of inertia of the mechanism changes to ensure stable operation in the start-up mode carried out with a powerup sensor. Therefore, an additional internal stator current control circuit subject to the motor speed control circuit is introduced into the automatic control system of a synchronized electric drive built on a current inverter to increase the stability. The internal circuits for regulating phase currents of the stator are based on a relay current controller. The block diagram of the frequency synchronized asynchronous electric drive is shown in Fig. 2. The system of the frequency-controlled synchronized asynchronous electric drive uses a standard converter that feeds the stator winding. It contains an uncontrolled rectifier, the output of which is connected to the input of a controlled autonomous inverter. The electromagnetic field produced by the stator winding is determined by the output parameters of the frequency converter: the current $I_{1}$ and the frequency $f_{1}$. The device contains a rectifier 1 and an inverter 2, an electric motor 3 . The inverter is made on fully controlled valves - IGBT-transistors. The speed sensor 5 is mounted on the motor shaft, the sensors 4 supply the voltage and current signals to the control system 6. The block diagram of the control unit implemented in the Matlab Simulink software pack is shown in Fig. 3.

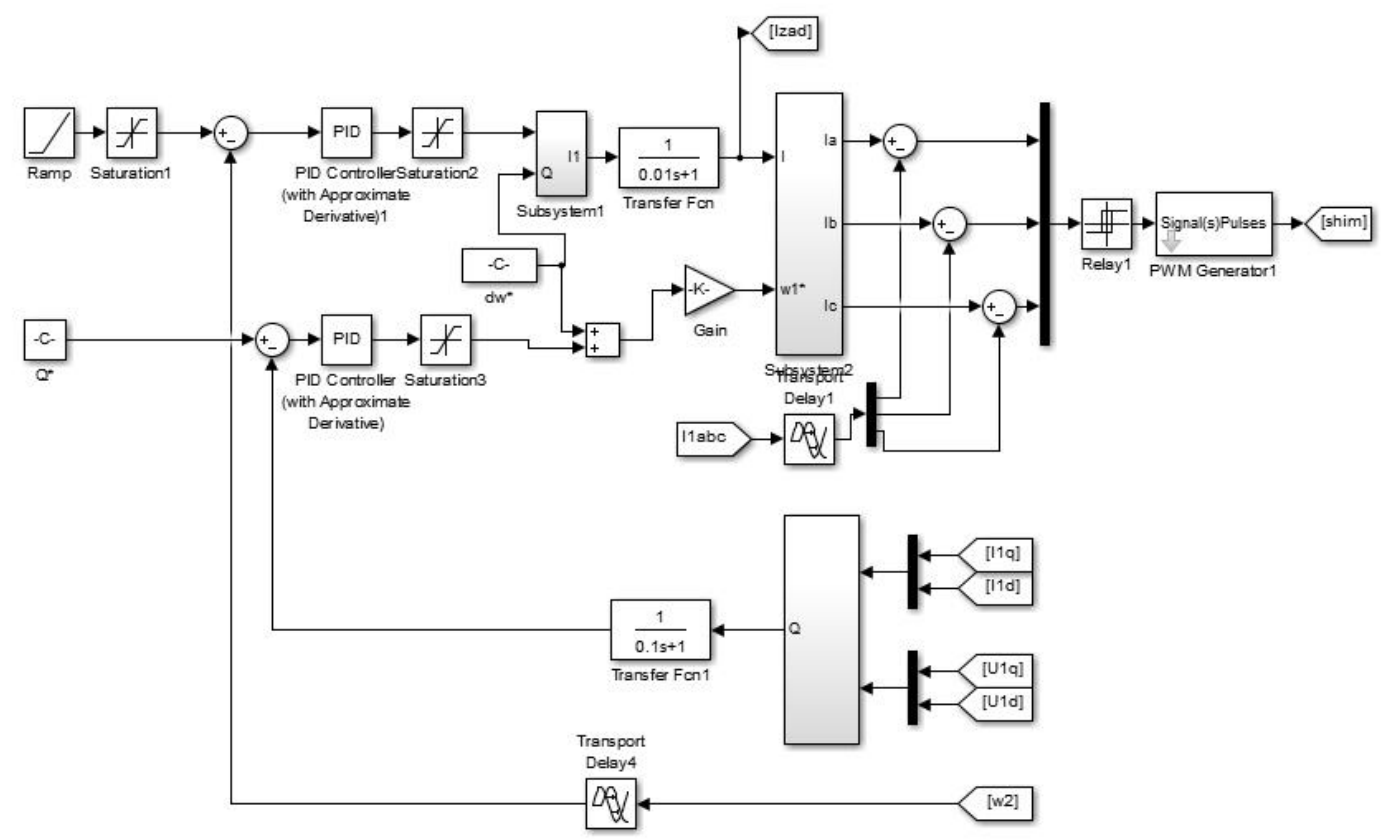

Fig. 3. Control unit diagram. 


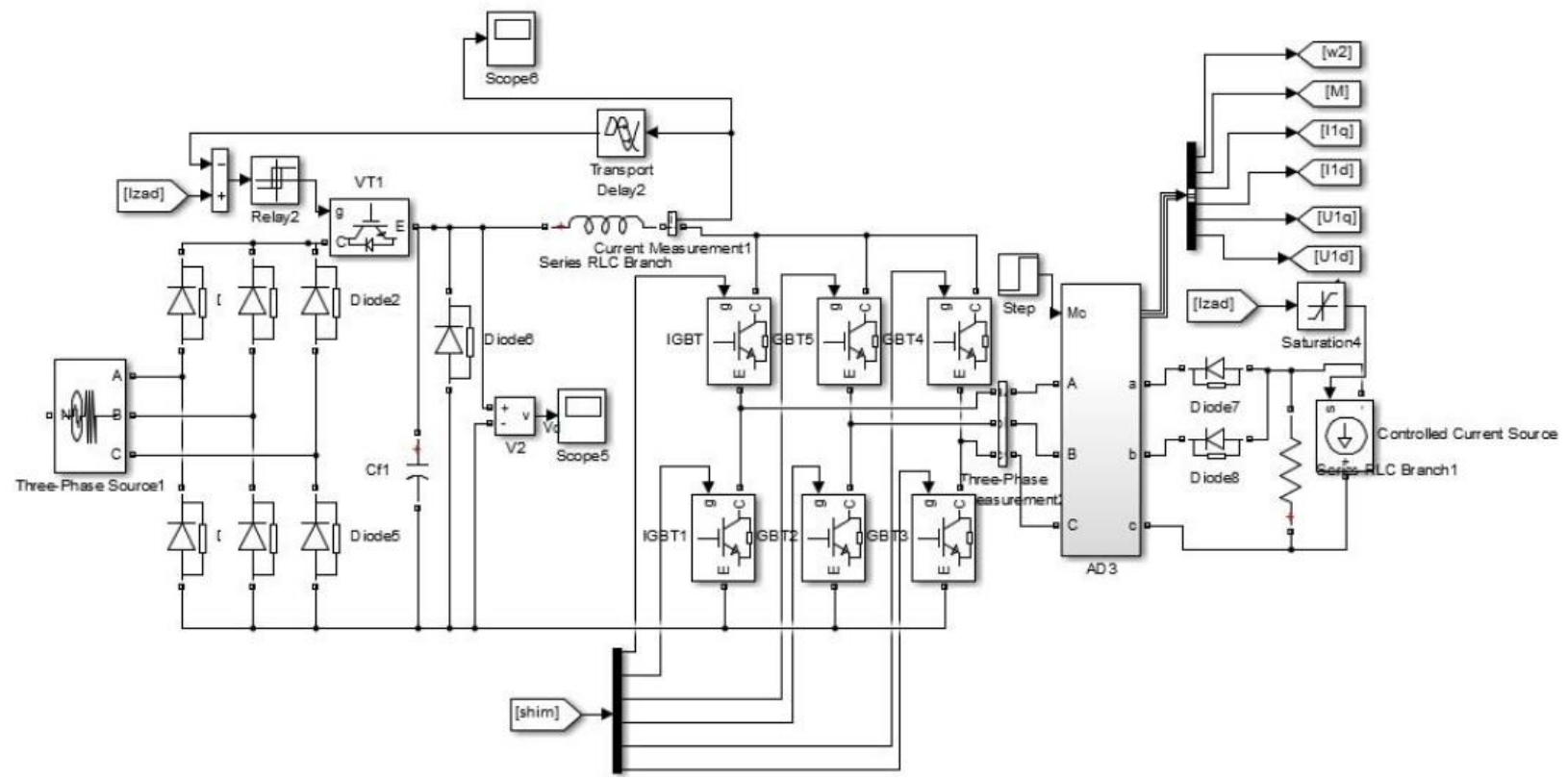

Fig. 4. Model of the synchronized asynchronous electric drive.

The stator current frequency is generated using the power-up sensor in the start-up mode. When reaching the given stator current frequency, the control system switches to the operating mode at the required speed. The current regulator operates according to the relay control. As a result of the comparison, we get the difference between the given and the actual values of the current in phases at the adders outputs [6]. The received signals are sent to the hysteresis inputs operating according to the following algorithm:

- when reaching the difference between the phase current set value and the phase current measured value of the threshold upper limit, the upper-arm valve is switched on and the lower-arm valve of the corresponding phase is switched off;

- when reaching the difference between the phase current set value and the phase current measured value of the threshold lower limit, the upper-arm valve is switched off and the lower-arm valve of the corresponding phase is switched on.

Then the signal from the hysteresis output is fed to the output of the transistors control of the corresponding phase. The switching frequency of power transistors can be $10 \mathrm{kHz}$.

The torque angle $\theta$ is an important parameter for synchronous mode of an asynchronous motor [3]:

$$
q=\int \omega_{1} d t-\int \omega_{2} p_{n} d t
$$

where $\omega_{1}-$ the circular frequency of the stator voltage; $\omega_{2}-$ the rotor speed; $p_{n}-$ the number of pairs of motor poles. The torque angle control circuit operates in the control system, which corrects the stator current frequency setting signal to reduce the rotor oscillations arising during the motor start-up. Adjustment of the torque angle control circuit is made considering the following features:
- the oscillation amplitude of the torque angle depends both on the electrical and mechanical parameters of the motor;

- static load on the drive shaft is determined by the average torque angle for the period of free oscillations [7];

- to quench the oscillations arising in the drive, according to classical mechanics, it is necessary to apply the control action in one phase with the oscillations of the system. The adjusting factor is chosen out of necessity to adjust the torque angle rapidly [8].

The factor is set to less than unity to have a stable system, but increasing it, the operating speed of the torque angle control circuit increases. Hence, it is practical to determine it independently for each separate electric drive [9]. The time constant $T$ is determined by the free oscillations frequency of the electric drive system, it should not be less than this frequency. Excessive increase leads to a degradation in the system dynamic characteristics when the load on the shaft changes. Thus, the time constant is recommended to be chosen in the limit:

$$
(1 \div 2) T_{0}
$$

where $T_{0}$ is the period of free oscillations of the electric drive open system.

The corrected current signals at the output of the phase currents unit are determined by the formulas:

$$
\begin{aligned}
& I_{a}{ }^{*}=I_{m} \sin \left(\left(\omega+\omega_{0}\right) t\right) \\
& I_{b}{ }^{*}=I_{m} \sin \left(\left(\omega+\omega_{0}\right) t+120^{\circ}\right) \\
& I_{c}{ }^{*}=I_{m} \sin \left(\left(\omega+\omega_{0}\right) t+240^{\circ}\right)
\end{aligned}
$$

where $\omega_{0}$ is the correction signal.

In the start-up mode, the rate of change of the frequency signal is set by the power-up sensor tuned in 
accordance with the value of the total inertia moment of the drive and the required acceleration [10].

If the selected acceleration is slightly overrated and the motor rotor does not have time to change its speed with a given tempo, the signal corrects the acceleration rate and stator current frequency.

\section{Result}

The proposed control system was modeled in the Matlab Simulink software environment (Fig. 4) [11]. The results of the simulation are shown in Fig. 5.

\section{Conclusions}

The synchronous asynchronous electric drive control system is designed and simulated in the work. Since the stability of the considered electric drive is greatly influenced by the value of the torque angle, the prompt speed setting was corrected in the control system in order to maintain this angle constant in the start-up mode. The vector correction of variables introduced into the scalar control system allows to orient the stator current vector relative to the rotor flux-linkage vector at any moment. Thus, the starting torque is stabilized in the synchronized frequency drive control system. This allows to use this ED on mechanisms with a cyclic operation mode.

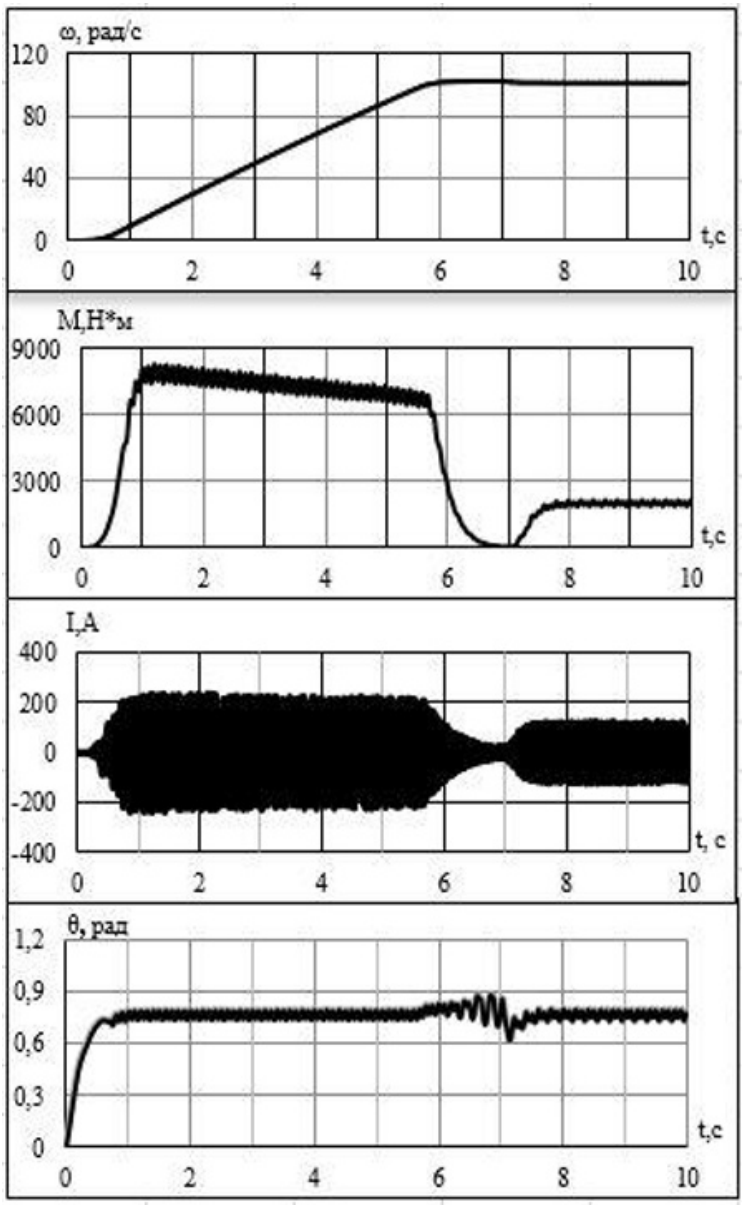

Fig. 5. Simulation results of a synchronized asynchronous electric drive.

\section{Acknowledgements}

The paper was powered by research grant RFBR 19-48-480001 "Development, investigation and optimization of energy-saving electrical and electrically driven automated systems for plasma, electrometal slag and induction technologies and units".

\section{References}

[1] V.N. Meshcheryakov, Systems of an adjustable asynchronous electric drive for hoisting and transport mechanisms: monograph (Lipetsk, LSTU, 112, 2005)

[2] G.G. Sokolovsky, $A C$ electric drives with frequency control (Moscow, Academy, 272, 2006)

[3] V.N. Meshcheryakov, P.N. Solomatin, Synchronized asynchronous electric drive with frequency control, News of HEIs, Electromechanics 2, 51-57 (2009)

[4] Y.I. Gracheva, N.V Chernova, A.I Fedotov, E.A. Fedotov, Local Fourier transformation application for mathematic modeling of synchronous machine valve actuator, Journal of engineering and applied sciences 11, 1, 29392945 (2016)

[5] V.N. Meshcheryakov, A.M. Bashlykov, O.V. Meshcheryakova, System of scalar frequency control of synchronized asynchronous machine with power supply of stator and rotor windings from autonomous current inverter, HTCS'2012: materials of International scientific and technical conference, Stary Oskol TNT, 50 (2012)

[6] V.N. Meshcheryakov, D.S. Sibirtsev, Frequency asynchronous electric drive with correction of phase shift between moment-forming vectors, Control systems and information technologies $\mathbf{2}$, 68, 48-57 (2017)

[7] Y.I. Gracheva, O.V. Naumov, Operating Mode Influence on Probability Characteristics of Electric Devices, Journal of engineering and applied sciences 11, 1, 2934-2938 (2016)

[8] H. Rehman, L. Xu, Alternative energy vehicles drive system: Control, flux and torque estimation, and efficiency optimization, IEEE Trans. Veh. Technol 60, 3625-3634 (2011)

[9] J. Rodriguez, R.M. Kennel, J.R. Espinoza, M. Trincado, C.A. Silva, C.A. Rojas, High performance control strategies for electrical drives: an experimental assessment, IEEE Trans. Ind. Electron. 59, 812-882 (2012)

[10] V.N. Meshcheryakov, D.V. Lastochkin, Z.M. Shakurova, S. Valtchev, Energy saving system of cascade variable frequency induction electric drive, SES 2019, Kazan, E3S Web of Conferences, 01037 (2019)

[11] I.V. Chernykh, Modeling of electrical devices in MATLAB, SimPowerSystems and Simulink (St. Petersburg, St. Pete, 288, 2008) 